\title{
Design and Implementation of Wearable Photovoltaic Cell
}

\author{
Ms. G. Jegadeeswari \\ Assistant Professor \\ Department of Electrical \& Electronics Engineering \\ Academy of Maritime Education \& Training (AMET) \\ (Deemed University) \\ Kanathur, Tamil Nadu \\ $\&$ \\ Ms. K. Rekha \\ Assistant Professor \\ Department of Electrical\& Electronics Engineering \\ Sri Sairam Institute of Technology \\ Chennai, Tamil Nadu, India
}

\begin{abstract}
Nowadays, Product Integrated Photovoltaic (PIPV) plays a major role in renewable energy sources, particularly for the infantry soldiers and defense industry. During war field, soldiers having various harms such as very cold temperature and some region like hot weather. Hence, in this risky process they cannot always be having the tools with battery for communication equipment and still in case they are prepared with batteries, it will be a big burden for them. Thus, to overcome this difficulty, a light weight wearable solar device being designed especially for the warrior. The proposed research contains a design, which is a portable-charging unit that utilizes flexible solar cells. The flexible solar cells are tested in different environment to find out the best arrangement and design for soldier's bag.
\end{abstract}

Keywords: Product Integrated Photovoltaic (PIPV), Soldiers, Wearable Solar Jacket, LCD, Aurdino Embedded Board.

\section{Introduction}

Despite, modern advances in military technology, the soldier of infantry continues to play an important role in defense. It is still the infantry soldier in the age of stealth jets, nuclear munitions, and guided weapons that examines and secures a location to determine whether the target area is cleared and the enemy defeated. The modern infantry soldier uses today's available electronic technology and resources to penetrate into hostile and challenging terrain, wherein armored vehicles cannot trespass and overcome the enemy [1]. The critically important power requirements 
of modern soldier in accordance with electrical technology is always much higher than that of civilian counterpart. In addition to this, the operating environment is far more aggressive and demanding than those of civilian applications and loss of power will endanger the life of infantry soldier [2][3]. This is the main reason behind massive battery overload, which accounts for almost 25 percent of overall load of equipment (including deadly, safety and communication). However, there is an uncontested restriction of maneuverability and operational flexibility as well as substantial physical and cognitive strain due to the aforementioned fact. Recently, the advances in sustainable energy and in particular advanced flexible and wearable photovoltaic (PV) technologies could provide a potential solution to this problem by eliminating or significantly reducing battery usage [3]. This research mission is studied by the Solar Soldier Programme, which is partly funded by the MOD's Defense Science and Technology Laboratory (DSTL) in UK and Engineering and Physical Sciences Research Council (EPSRC).

\section{Objective}

- To design a light weight wearable solar device being designed especially for the warrior

- To miniaturize by combining with the greater flexibility of solar cells towards leading to new opportunities for wearable solar technology

- To charge through a USB connection integrated into clothing thereby bringing an extra layer of convenience for users

- To swathe of electronic devices, such as mobile phones, could be charged on the move

\section{Solar Panel and Its Types}

Photovoltaic modules use light energy (photons) from Sun to generate electricity through photovoltaic effect. The majority of modules use wafer-based crystalline silicon cells or thin-film cells. The structural (load carrying) member of a module can either be top layer or back layer. The cells must also be protected from mechanical damage and moisture [4]. Most modules are rigid, but semi-flexible ones based on thin-film cells are also available. The cells must be connected electrically in series, one to another. Externally, most of photovoltaic modules use MC4 connector's type to facilitate easy weatherproof connections to the rest of the system. 

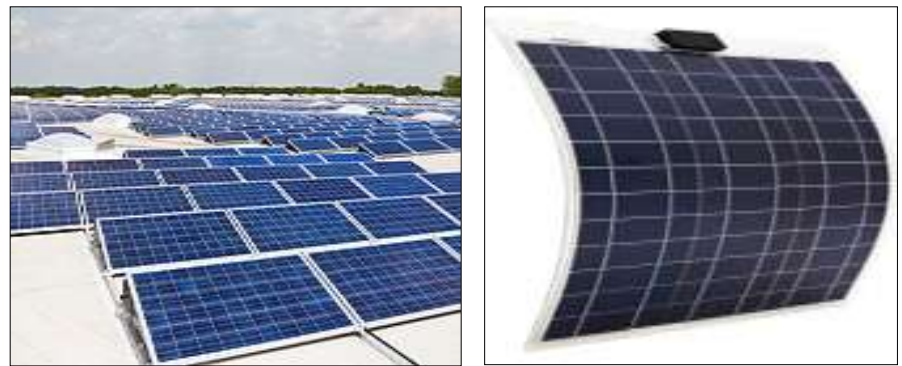

Fig 1: Solar Grid
Fig 2: Semi Flexible Solar Cell

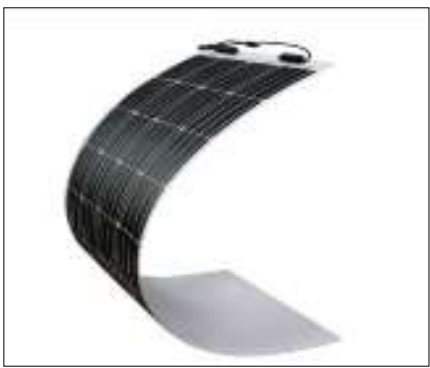

Fig 3: Flexible Solar Cell

Module electrical connections are made in series to achieve a desired output voltage or in parallel to provide a desired current capability. The conducting wires that take the current off the modules may contain silver, copper or other non-magnetic conductive transition metals. Bypass diodes may be incorporated or used externally, in case of partial module shading, to maximize the output of module sections still illuminated [5]. Moreover, special solar PV modules include concentrators in which light is focused by lenses or mirrors onto smaller cells. This enables the use of cells with a high cost per unit area (such as gallium arsenide) in a cost-effective way. Solar panels also use metal frames consisting of racking components, brackets, reflector shapes, and troughs to better support the panel structure. It has light weight and thinnest panels and we can achieve highest output per square foot. Moreover, it is optimal for canvas bimini / dodger installations on boats and yachts. Huge variety of sizes and shapes are available. The Fig. 2 shows semi flexible solar cell, wherein thin film solar panels come from a second-generation solar cell, which is made by layering one or more thin films of photovoltaic material on a "base", a substrate of plastic, glass or metal. The final result is a panel much thinner than the average of mono and polycrystalline solar panels, which makes them flexible and lighter. This is shown in Fig 3, which means the roof has to support a very light structure without racks. Also, producing these panels also has a lower cost, so the final price is very competitive. Table 1 shows the comparative study of various solar panels [6-7].

Table 1: Comparison of Solar Panels

\begin{tabular}{|c|c|c|c|}
\hline $\begin{array}{l}\text { Solar Panel } \\
\text { Properties }\end{array}$ & $\begin{array}{l}\text { Rigid Solar } \\
\text { Panel }\end{array}$ & $\begin{array}{c}\text { Semi Flexible } \\
\text { Panel }\end{array}$ & Flexible Solar Panel \\
\hline Size & $\begin{array}{c}\text { Very Large } \\
\text { Depends on Need }\end{array}$ & Compact & $\begin{array}{l}\text { Small Dimension can } \\
\text { also be Designed }\end{array}$ \\
\hline Weight & Very Bulk & Low Weight & Very Low Weight \\
\hline Efficiency & Low & Moderate & High \\
\hline Cost & Very High & Optimal & Low Cost \\
\hline
\end{tabular}

\section{Arduino Board (Microcontroller)}

Aurdino is a type of open source computer hardware and software company comprising of project and user community that designs and manufactures single 
board microcontrollers and microcontroller kits for building digital devices and interactive objects that can sense and control objects in the physical and digital world. The Aurdino boards are able to read inputs-light on a sensor, a finger on a button and turn it into an output - activating a motor, turning on an LED. Arduino Uno is a microcontroller board based on the ATmega328 (datasheet). It has 14 digital input/output pins (of which 6 can be used as PWM outputs), 6 analog inputs, a $16 \mathrm{MHz}$ quartz crystal, a USB connection, a power jack, an ICSP header and a reset button. Uno is the best board to get started with electronics and coding. If this is your first experience tinkering with the platform, the Uno is the most robust board you can start playing with [2-4]. Uno is the most used and documented board of the whole Aurdino family. The parts of Arduino board shown in Fig 4.

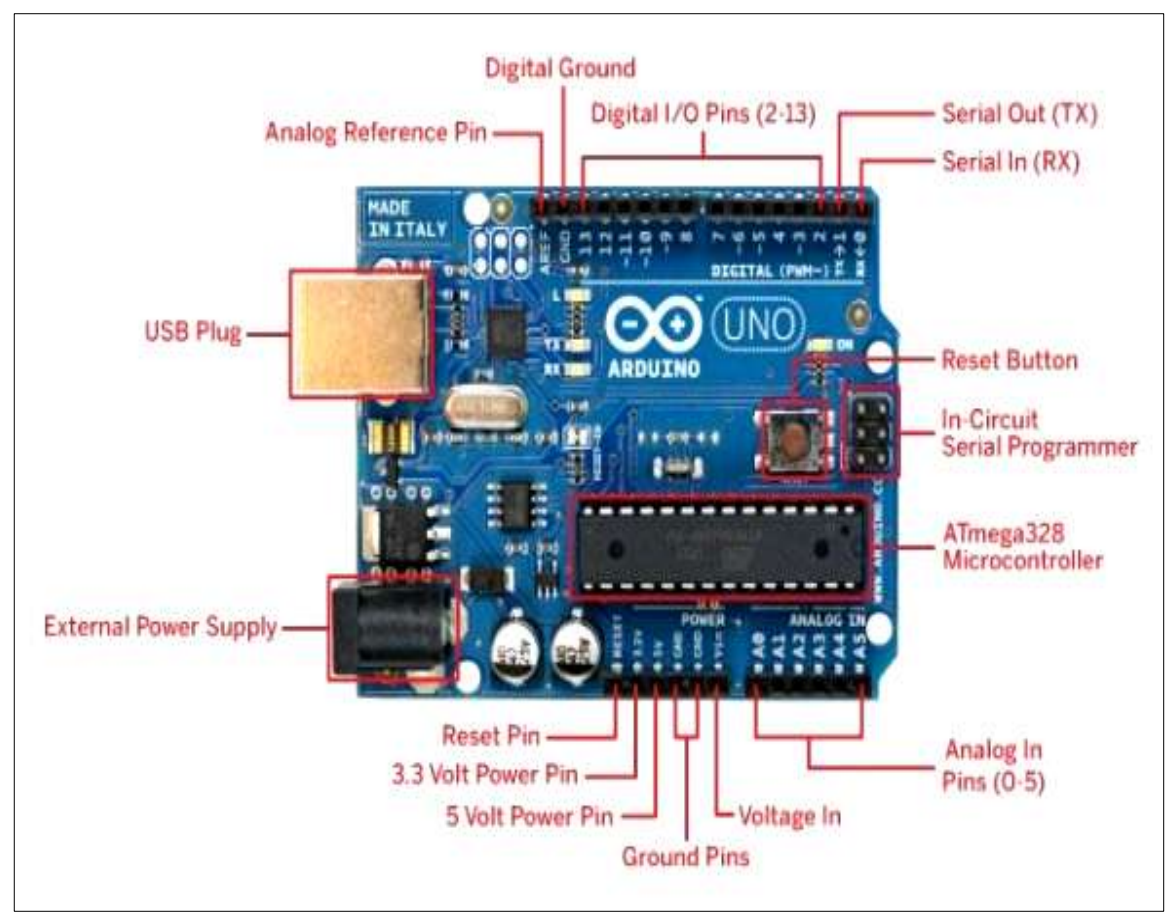

Fig 4: Arduinouno Parts

Arduino Uno is a microcontroller board based on the ATmega328 (datasheet). It has 14 digital input/output pins (of which 6 can be used as PWM outputs), 6 analog inputs, a $16 \mathrm{MHz}$ quartz crystal, a USB connection, a power jack, an ICSP header and a reset button. It contains everything needed to support the microcontroller; simply connect it to a computer with a USB cable or power it with a AC-to-DC adapter or battery to get started. You can tinker with your Uno without worrying too much about doing something wrong, worst case scenario you can replace the chip for a few dollars and start over again. 'Uno' means one in Italian and has been chosen to mark the release of Arduino Software (IDE) 1.0. The Uno board and version 1.0 of Arduino Software (IDE) were the reference versions of Arduino, now 
evolved to newer releases. Uno board is the first in a series of USB Arduino boards and reference model for Arduino platform. Moreover, for an extensive list of current, past and outdated boards one can see to Arduino index of boards. The name Arduino comes from a bar in Ivrea, Italy, whereas some of the founders of project used to meet. The bar was named after Arduino of Ivrea, who was the margrave of March of Ivrea and King of Italy [8].

\section{Hardware Implementation}

A standard monocrystalline or polycrystalline solar cell is made up of silicon wafers. They are typically up to 200 micrometers thick, which is slightly thicker than a human hair. Thus, in order to make a "semi-flexible" solar cell, those silicon wafers must be sliced down to just a few micrometers wide. Also, using these ultra-thin silicon wafers gives solar cell many unique properties, including flexibility for some models. The wearable solar cell is shown in the Fig 5a [9]. A solar cell or photovoltaic cell is an electrical device that converts the energy of light directly into electricity by the photovoltaic effect, which is a physical or chemical phenomenon. The block diagram of proposed system is shown in the Fig $5 b$.

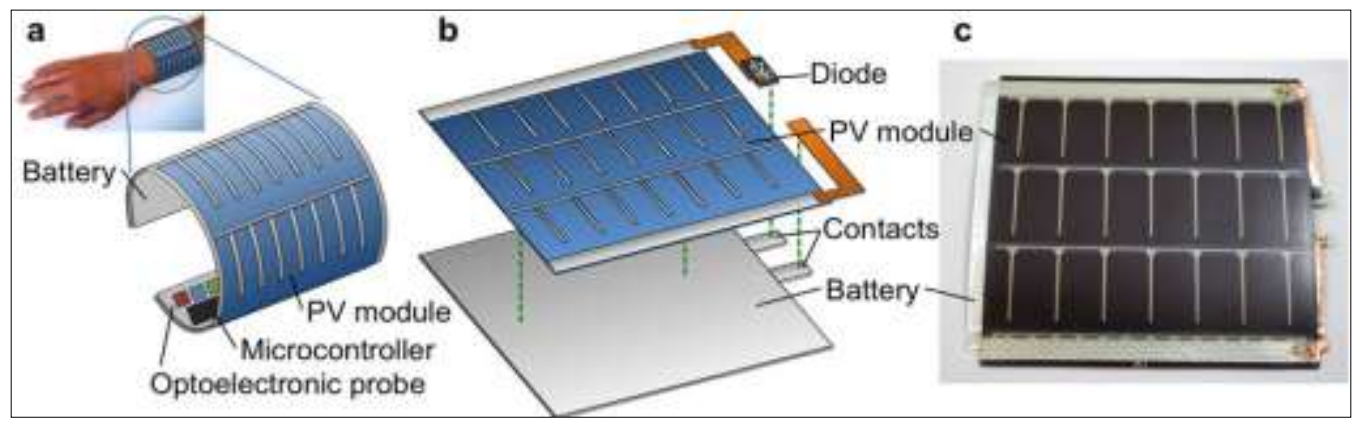

Fig 5a: Wearable Solar Cell

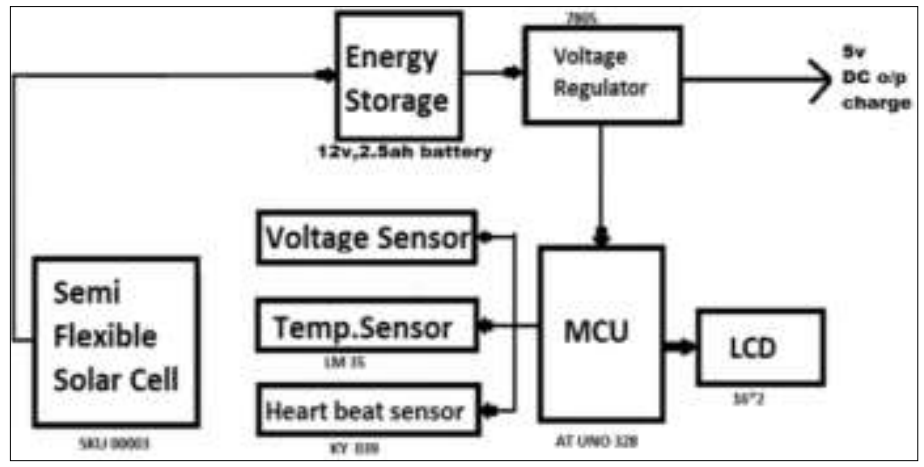

Fig 5b: Block Diagram representation of Proposed System 
A voltage sensor is able to determine and even monitor and measure the voltage supply from the flexible solar panel. It is then able to take those measurements and turn them into a signal that one will then be able to read. The LM35 is one kind of commonly used temperature sensor that can be used to measure temperature with an electrical o/p comparative to the temperature (in ${ }^{\circ} \mathrm{C}$ ). It can measure temperature more correctly compare with a thermistor. This sensor generates a high output voltage than thermocouples and may not need that the output voltage is amplified [10]. The LM35 temperature sensor is used to detect precise centigrade temperature. The output of this sensor changes describes the linearity. The $\mathrm{o} / \mathrm{p}$ voltage of this IC sensor is linearly comparative to the Celsius temperature. The operating voltage range of this LM35 ranges from $-55^{\circ}$ to $+150^{\circ} \mathrm{C}$ and it has low-self heating. This is operated under 4 to 30 volts. The most extensively used electronic devices are operational amplifiers, which are certain kind of differential amplifiers. The variation between input terminals amplifies the circuit is shown in Fig 6 [5] [6].
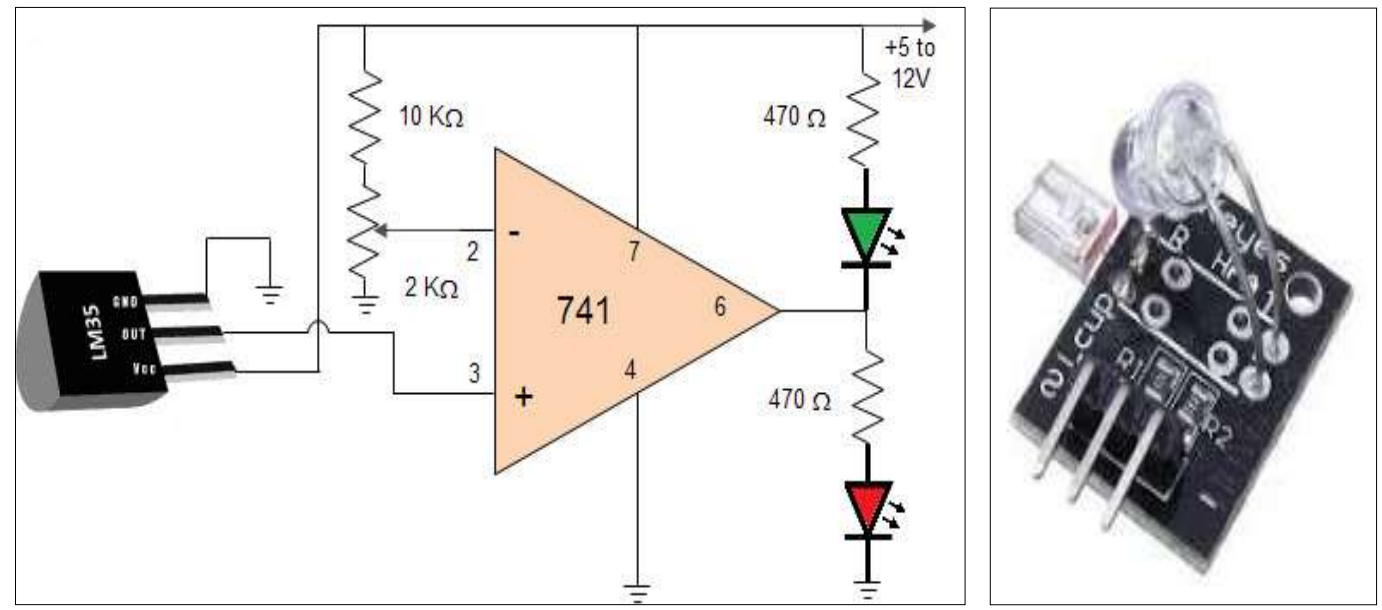

Fig 6: Temperature Sensor internal Circuit diagram

The liquid crystal displays (LCDs) are commonly used to display data in devices such as calculators, microwave ovens and many other electronic devices. Fig 7 indicates the method to use a 16x2 LCD with an Aurdino. The 16x2 LCD used in this experiment has a total of 16 pins. 


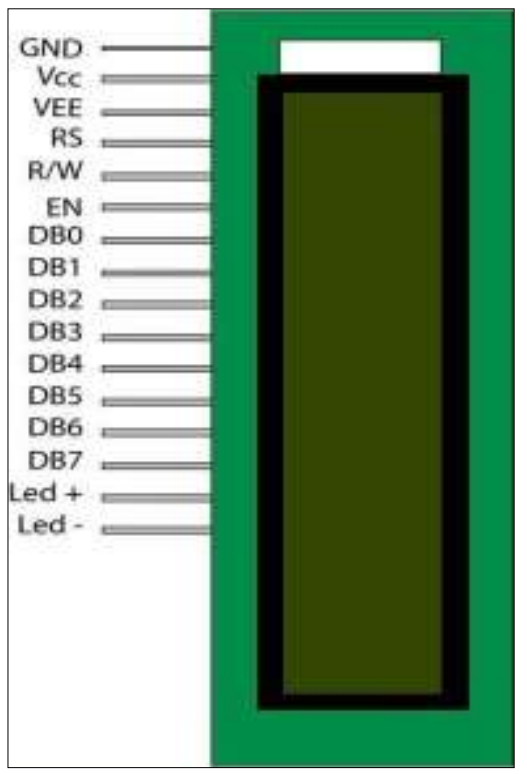

Fig 7: LCD Display

The number of times the heart beats per minute (BPM) is termed as heart beat rate, wherein the pulse can be felt through any artery that lies close to skin. Heartbeat sensor provides a simple way to study the function of heart, which can be measured based on the principle of psycho-physiological signal and used as a stimulus for the virtual-reality system.

The amount of blood in the finger changes with respect to time and signals are recorded accordingly and indicated in Fig 8.

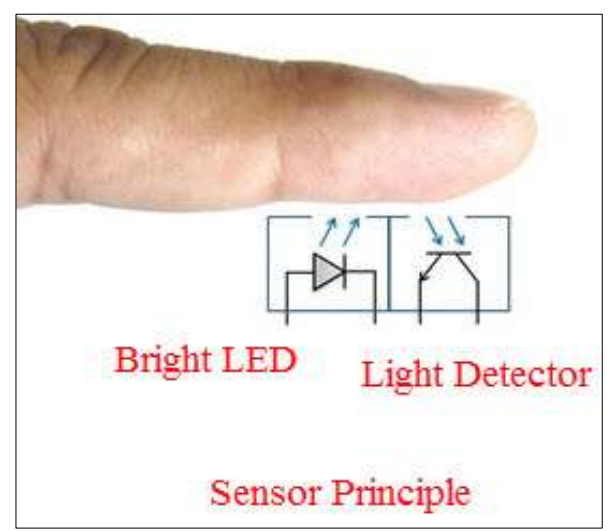

Fig 8: Heart Beat Sensor

The sensor shines a light lobe (a small very bright LED) through ears and measures the light that gets transmitted to Light Dependent Resistor (LDR). The amplified 
signal gets inverted and filtered in the Circuit. Thus, in order to calculate the heart rate based on blood flow to the fingertip, a heart-rate sensor is assembled with the help of LM358 OP-AMP for monitoring heartbeat pulses, wherein each Sensor Output is shown in Fig 9 indicated below:

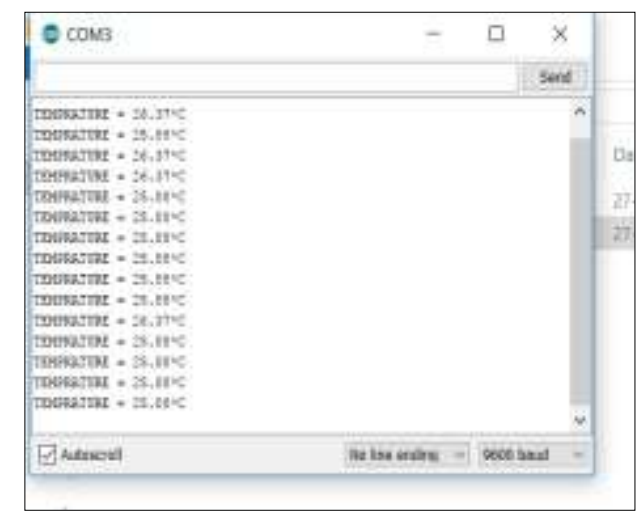

Fig 9: Output of Temperature Sensor

The Output of Temperature, Voltage and Heartbeat sensor is shown in Fig 10.

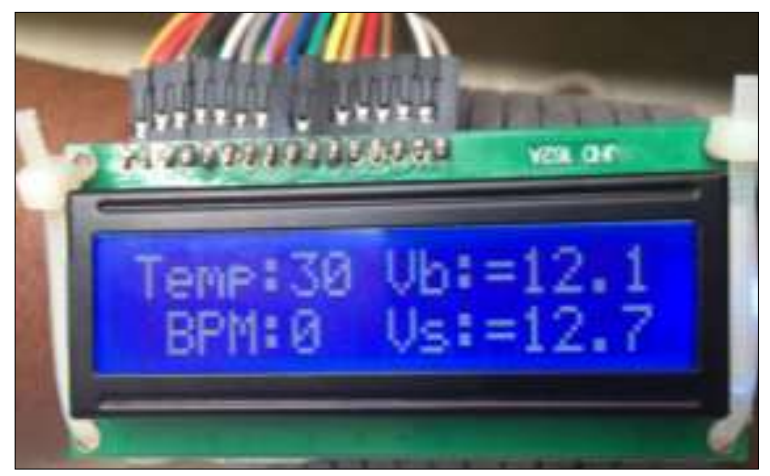

Fig 10: Output of Temperature, Voltage and Heart Beat Sensor

\section{Suggestion \& Conclusion}

Product Integrated Photovoltaic (PIPV) plays a major role in renewable energy sources, particularly for the infantry soldiers and defense industry. During war field, soldiers having various harms such as very cold temperature and some region like hot weather. Hence, in this risky process they cannot always be having the tools with battery for communication equipment and still in case they are prepared with batteries, it will be a big burden for them. The proposed research contains a design, which is a portable-charging unit that utilizes flexible solar cells. The flexible solar cells have to be tested in different environment and climate conditions to find out 
the best arrangement and design for soldier's bag. The hardware is developed to help soldiers by monitoring the heartbeat, temperature and to charge the communication devices. Therefore, it requires thorough constant testing, standardization and improvement. Moreover, to overcome the critical battery down situation of communication devices semi flexible solar panel is chosen and fabricated within the soldier's bag through programmed embedded controller so as to use it in emergency situation. This chapter provides appropriate solution to military soldier at war fields to carryout light weight wearable solar device as charging units than carrying heavy electrical equipments.

\section{References}

[1] Chaturvedi, A., Dolk, D. R. \& Drnevich, P. L. (2011). Design Principles for Virtual Worlds, MIS Quarterly, Vol.35, No.3, pp.673-684.

[2] Yang, J., Rahmatalla, S., Marler, T., Abdel-Malek, K. \& Harrison, C. (2007). Validation of Predicted Posture for the Virtual Human Santos ${ }^{\mathrm{TM}}$, Digital Human Modelling, HCII 2007, LNCS 4561, pp.500-510.

[3] Blount, E. M., Ringleb, S. I., Tolk, A., Bailey, M. \& Onate, J. A. (2011). Incorporation of Physical Fitness in a Tactical Infantry Simulation, The Journal of Defence Modelling and Simulation: Applications, Methodology, Technology, Vol.12, No.4, pp.345-352.

[4] Parida, B., Iniyan, S. \& Goicm, R. (2011). A Review of Solar Photovoltaic Technologies, Renewable and Sustainable Energy Reviews, Vol.15, No.3, pp.1625-1636.

[5] Chaar, L. E., Lamont, L. A. \& Zein, N. E. (2011). Review of Photovoltaic Technologies, Renewable and Sustainable Energy Reviews, Vol.15, No.5, pp.2165-2175.

[6] Paraskevopoulos, I. \& Tsekleves, E. (2011). Simulation of Photovoltaics for Defence and Commercial Applications by Extending Existing 3D Authoring Software - A Validation Study, In Proceedings: International Conference on Simulation and Modelling Methodologies, Technologies and Applications (SIMULTECH), Netherlands, Vol.3, No.4, pp.28-31.

[7] Randall, J., Bharatula, N., Perera, N., Von Buren, T., Ossevoort, S. \& Troster, G. (2011). Indoor Tracking using Solar Cell Powered System: Interpolation of Irradiance. In: International Conference on Ubiquitous Computing, Vol.5, No.3, pp.2345-2352. 
[8] Schubert MB, Werner JH, 2006, Flexible Solar Cells for Clothing, Materials Today, Vol.9, No.6, pp.456-467.

[9] Chowdhury, B., Dobson, I., Dong, Z. Y., B. Gou, B., Hawkins, D. L. \& Huang, Z. (2008). Initial Review of Methods for Cascading Failure Analysis in Electric Solar Power Transmission Systems, In IEEE Power and Energy Society General Meeting - Conversion and Delivery of Electrical Energy in the 21st Century, Vol.8, No.4, pp.1-8.

[10] Jegadeeswari, G., Veerakumar, P. \& Anand Kumar, A. K. (2019). Solar Power Synchronization with Main Bus Bar in VLCC using FPGA Technique, Universal Review, Vol.8, No.2, pp.117-120. 